Ri ng constructi on vi a pseudo- i nt ramol ecul ar hydrazonati on using bi functi onal $\delta$-keto nitrile

\begin{tabular}{|l|l|}
\hline 著者 & $\begin{array}{l}\text { H r ao Shot ar o, Kobi ro Kazuya, Sawayama Jun, } \\
\text { Sai go Kazuhi ko, N shi waki Nagat oshi }\end{array}$ \\
\hline $\begin{array}{l}\text { j our nal or } \\
\text { publ i cat i on t i t l e }\end{array}$ & Tet r ahedr on Let ter s \\
\hline vol une & 53 \\
\hline number & 1 \\
\hline page r ange & $82-85$ \\
\hline year & 2012 \\
\hline URL & ht t p: //hdl . handl e. net /10173/1340 \\
\hline
\end{tabular}




\title{
Ring construction via pseudo-intramolecular hydrazonation using bifunctional $\delta$-keto nitrile
}

\author{
Shotaro Hirao, Kazuya Kobiro, Jun Sawayama, Kazuhiko Saigo and Nagatoshi Nishiwaki * \\ School of Environmental Science and Engineering, Kochi University of Technology, Tosayamada, Kami, Kochi 782-8502, Japan
}

\begin{abstract}
ARTICLE INFO
ABSTRACT

Article history:

Received

Received in revised form

Accepted

Available online

\section{Keywords:}

An $\alpha$-nitro- $\delta$-keto nitrile efficiently reacted with hydrazines at room temperature, even in the absence of a catalyst, to afford the corresponding hydrazones; the reactions proceeded through a pseudo-intramolecular process. The hydrazone derived from hydrazine monohydrate underwent water-assisted cyclization, which yielded the corresponding diazepine. The hydrazones derived from 4-nitrophenylhydrazine and 2,4-dinitrophenylhydrazine were converted to pyridazines upon being heated in DMSO.
\end{abstract}

cyclization

heterocycles

hydrazones

imines

pseudo-intramolecular hydrazonation
2009 Elsevier Ltd. All rights reserved.
The development of highly efficient synthetic methods for various organic compounds is crucial for the efficient utilization of carbon resources and for low environmental impact. Reactions not requiring protecting groups or special reagents facilitate the simplification of manipulations from the viewpoint of atom economy. ${ }^{1}$ In order to improve reaction efficiency, the collision frequency of reactants should be increased. Generally, an intramolecular process proceeds faster than an intermolecular process because the spatial proximity increases the collision frequency of reaction sites. With regard to intermolecular processes, the use of reaction fields such as capsules, ${ }^{2}$ cages, ${ }^{3}$ bowls, $^{4}$ and micelles ${ }^{5}$ has been recognized as being effective because reactive substrates located close to each other make the reaction highly efficient.

In this context, we have demonstrated pseudo-intramolecular processes that proceed under very mild conditions. Indeed, $\alpha-$ arylated and $\alpha$-nitrated $\beta$-keto esters underwent transacylation ${ }^{6,7}$ with amines very smoothly and rapidly to afford the corresponding amides without any detectable by-products. In these reactions, the highly acidic keto ester reacted to form the corresponding ammonium salt with the amine immediately. Then, under equilibrium, the electrophilic keto ester and the nucleophilic amine were regenerated simultaneously and in close proximity. As a result, the reaction proceeded efficiently like an intramolecular process.

The $\alpha$-nitro- $\delta$-keto nitrile $\mathbf{1}^{8}$ also satisfies two criteria of a substrate that is to be used in a pseudo-intramolecular reaction: it has an acidic hydrogen and a reactive functional group in the

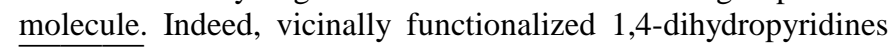

were synthesized upon treatment of the keto nitrile $\mathbf{1}$ with amines. ${ }^{9}$ Furthermore, the reaction of $\mathbf{1}$ with a diamine entailed tandem cyclization to afford a 1,7-diazabicyclo[4.3.0]nonane derivative, in which pseudo-intramolecular imination was a key step. $^{10}$ These results prompted us to study the pseudointramolecular reaction of $\mathbf{1}$ by using a hydrazine instead of a diamine as a dinucleophile (Scheme 1).

Initially, the keto nitrile $\mathbf{1}$ was allowed to react with unsubstituted hydrazine (2a) at room temperature in $\mathrm{CH}_{3} \mathrm{CN}$. After stirring for $48 \mathrm{~h}$, the formation of a spot different from those of $\mathbf{1}$ and 2a was confirmed on TLC. Structural analysis on the basis of spectral and analytical data clarified the formation of diazepine 7a (Scheme 2). ${ }^{11}$ The ${ }^{1} \mathrm{H}$ NMR signal of the methyne proton of $1\left(\mathrm{H}_{\mathrm{a}}\right)$ at $6.24 \mathrm{ppm}$ was considerably shifted to 4.88 ppm $\left(\mathrm{H}_{\mathrm{g}}\right)$. Moreover, the signals of the carbonyl and cyano carbons shifted from 207 to 138 ppm and from 112 to $172 \mathrm{ppm}$, respectively, in the ${ }^{13} \mathrm{C}$ NMR. These spectral changes indicate that $2 \mathbf{a}$ reacted with both functional groups of $\mathbf{1}$. The formation of $7 \mathbf{a}$ presumably proceeded via pseudo-intramolecular hydrazonation followed by nucleophilic attack on the cyano group. To confirm this hypothesis, the formation process of $\mathbf{7 a}$ was monitored by NMR spectroscopy. Just after the addition of 2a to a solution of $\mathbf{1}$ in $\mathrm{CD}_{3} \mathrm{CN}$, small signals of the hydrazinium salt 3a and the diazepine 7a were observed in the ${ }^{1} \mathrm{H}$ NMR, in addition to the signals of $\mathbf{1} .^{12}$ All the signals of $\mathbf{1}$ and 3a gradually disappeared, converting to the signals ascribed to $\mathbf{7 a}$. 


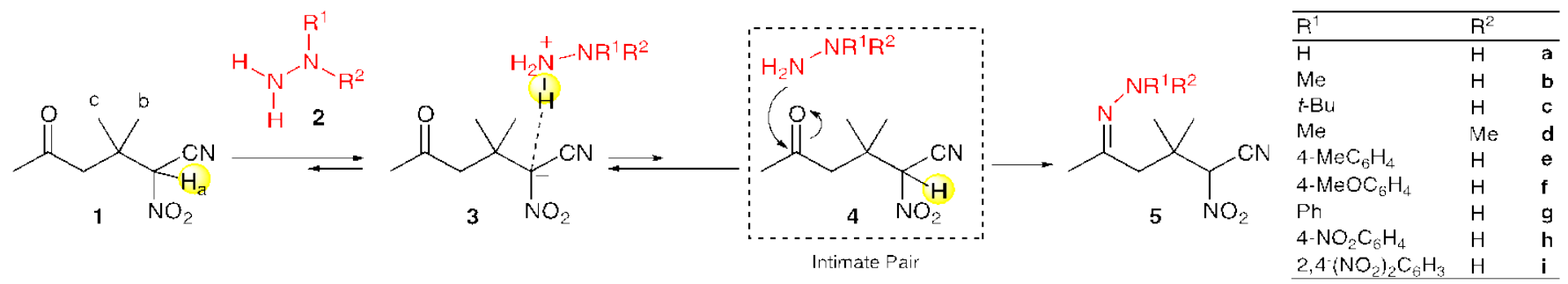

Scheme 1. Pseudo-intramolecular hydrazonation of the keto nitrile $\mathbf{1 .}$

On the other hand, methylhydrazine (2b) exhibited different reactivity under the same reaction conditions (Scheme 1). The reaction was considerably more complicated, giving an intractable mixture. Similar complications were also observed in the reactions with bulky t-butylhydrazine (2c) and $N, N$ dimethylhydrazine (2d). Hence, we monitored the reaction of $\mathbf{1}$ with $\mathbf{2 b}$ by ${ }^{1} \mathrm{H}$ NMR to elucidate the reaction behavior of the substrates. ${ }^{13}$ When $\mathbf{2 b}$ was added to a solution of $\mathbf{1}$ in $\mathrm{CD}_{3} \mathrm{CN}$, significant changes in the resonance corresponding to both

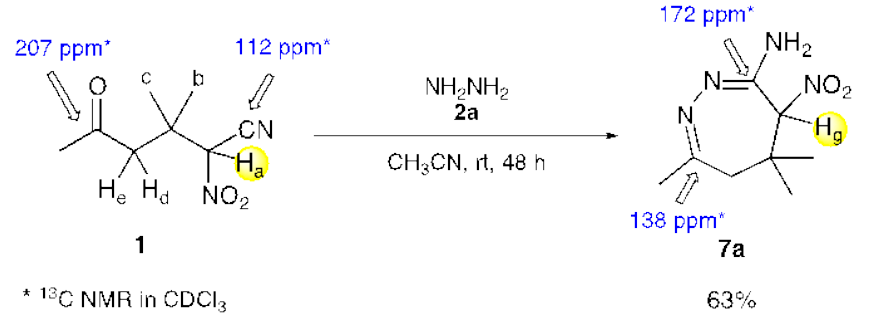

Scheme 2. Reaction of the keto nitrile $\mathbf{1}$ with the hydrazine $\mathbf{2 a}$.

reagents were observed: the singlet signal at $6.24 \mathrm{ppm}$, attributed to the methyne proton $\left(\mathrm{H}_{\mathrm{a}}\right)$ of $\mathbf{1}$, completely disappeared, and a<smiles>CC1=NNC(=N)C([N+](=O)[O-])C(C)(C)C1</smiles>

$6 a$<smiles>[R]N1N=C(C)CC(C)(CCC)C1=N</smiles>

Figure 1. Stabilization by tautomerization.

couple of singlets with equivalent intensities at around $1.2 \mathrm{ppm}$ and attributed to the two enantiotopic methyl groups (b and c) coalesced into a singlet signal at $1.23 \mathrm{ppm}$. In addition, the $\mathrm{N}$ methyl group of $\mathbf{2 b}$ shifted downfield by about $0.28 \mathrm{ppm}$. These observations indicate the formation of the hydrazinium salt $\mathbf{3} \mathbf{b}$. However, the reaction mixture became complex within several hours, even at room temperature. When DMSO- $d_{6}$ was employed as the solvent instead of $\mathrm{CD}_{3} \mathrm{CN}$, signals of ring products were not observed, too.

Considering the mechanism previously proposed for the reaction of $\mathbf{1}$ with 1,2-diamines, ${ }^{10}$ diazepines 7 a would be formed via the hydrazinium salt $\mathbf{3 a}$ and then the hydrazone 5a. Although the ${ }^{1} \mathrm{H}$ NMR showed no signal for $\mathbf{5 a}$, the observation of the signals of $\mathbf{3 a}$ supported the proposed mechanism. For alkylhydrazines $\mathbf{2 b}-\mathbf{d}$, the corresponding diazepines $\mathbf{6 b}, \mathbf{c}$ were possibly formed. However, the isolation of $\mathbf{6 b}, \mathbf{c}$ failed, probably because of their instability; the $N$-substituted diazepines $\mathbf{6 b}, \mathbf{c}$ could not be converted to a stable form such as $7 \mathbf{a}$ by tautomerization (Figure 1).
In the present reaction, another ring closure affording a sixmembered ring is also possible, as shown in Figure 2. To elucidate a plausible reaction pathway, density functional theory (DFT) calculations for the simplified model compound 8 bearing no methyl group at the $\beta$-position were performed. Comparison of the activation energies required to reach transition states showed that the activation energy for the seven-membered ring transition state is lower than that for the six-membered one. In the former case, water plays an important role; a water molecule binds to both the cyano group and the amino group to effect a water-assisted ring construction owing to the close proximity of
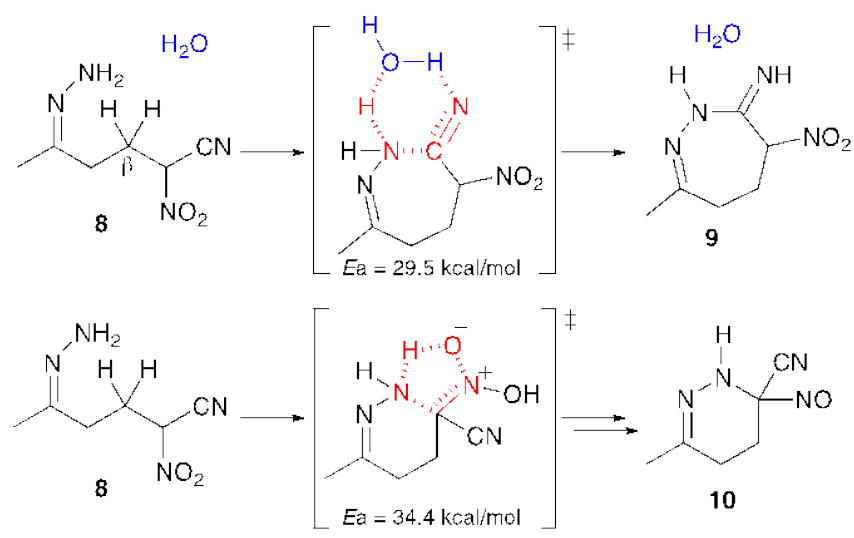

Figure 2. Comparison of two transition states from 8 to the sevenmembered and six-membered ring products $\mathbf{9}$ and 10, respectively.

the groups.

Although it was suggested that the hydrazone $\mathbf{5 a}$ was intermediately formed as mentioned above, 5a was too reactive to be isolated. Hence, we attempted the isolation of the hydrazones 5 through the use of aromatic hydrazines $\mathbf{2 e - i}$. In cases of 4-methylphenylhydrazine (2e) and 4methoxylphenylhydrazine (2f), the reactions were also too complex. In the reaction of $\mathbf{1}$ with phenylhydrazine (2g), the formation of the hydrazone $\mathbf{5 g}$ was confirmed by the ${ }^{1} \mathrm{H}$ NMR of a crude product. However, the isolation of $\mathbf{5 g}$ was not achieved because of its rather unstable nature. The use of electrondeficient 4-nitrophenylhydrazine and 2,4-dinitrophenylhydrazine $(\mathbf{2 h}, \mathbf{i})$ enabled us to isolate the hydrazones $\mathbf{5 h}, \mathbf{i}$ in quantitative

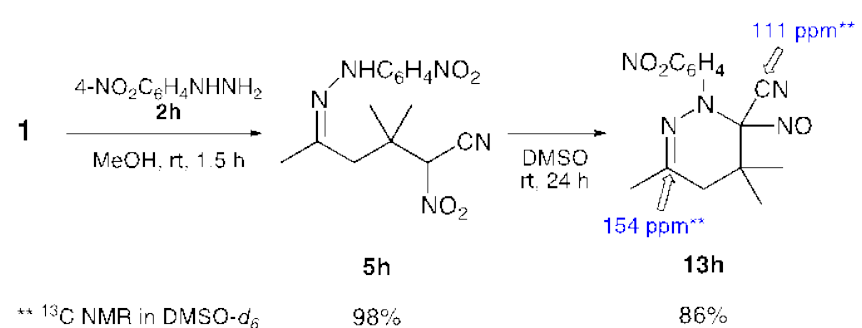

Scheme 3. Reaction of the keto nitrile $\mathbf{1}$ with the hydrazine $\mathbf{2 h}$.

yields: products spontaneously precipitated within $3 \mathrm{~h}$ of the addition of $\mathbf{2 h}, \mathbf{i}$ to a solution of $\mathbf{1}$ (Scheme 3). The structure of $\mathbf{5 h}$ 
was determined on the basis of its spectral and analytical data. ${ }^{14}$ Finally, the formation of the hydrazones was confirmed by the Xray single crystal analysis of $\mathbf{5 i}$ (see Supporting Information).

Hydrazone formation from the keto nitrile $\mathbf{1}$ and hydrazine $\mathbf{2 h}$ (1:1) was monitored by ${ }^{1} \mathrm{H}$ NMR spectroscopy in methanol- $d_{4}$ (used as the solvent), which dissolved the hydrazone homogeneously. As a result, approximately half of $\mathbf{2 h}$ was consumed within $1 \mathrm{~h}$ to afford $\mathbf{5 h}$ in $58 \%$ yield. The hydrazonation readily proceeded under mild conditions as a result of the pseudo-intramolecular nature of the reaction; in actuality, a similar reaction of $\mathbf{2} \mathbf{h}$ with acetone without involving any functional group to promote a pseudo-intramolecular process resulted in the formation of the corresponding hydrazone only in $28 \%$ yield after $1 \mathrm{~h}$ (Figure 3 ).

When the isolated hydrazone $\mathbf{5 h}$ was heated in DMSO at room

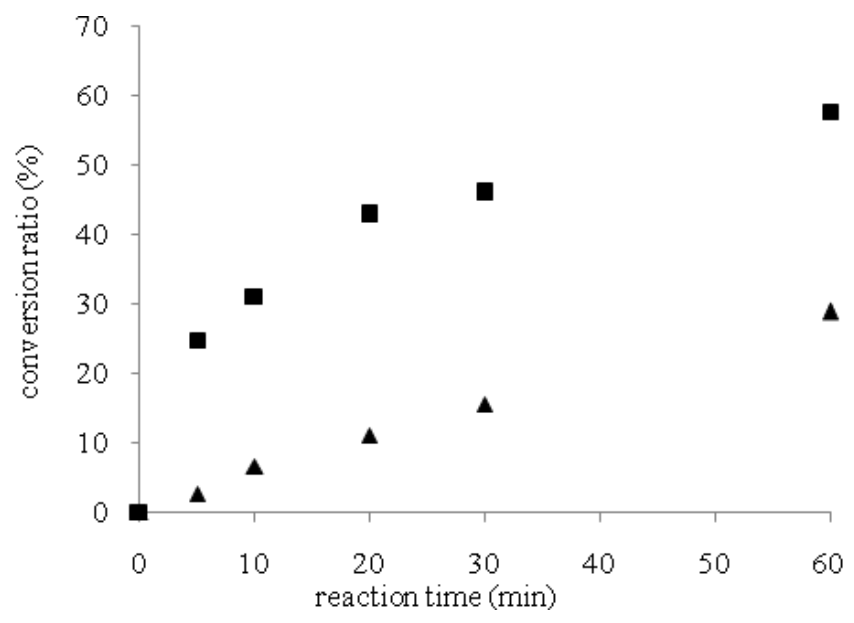

Figure 3. Comparison of the hydrazonation rate of the keto nitrile $\mathbf{1}$ $(\boldsymbol{\square})$ and acetone $(\boldsymbol{\Delta})$ with the hydrazine $\mathbf{2 h}$.

temperature for 1 day, a crystalline product was afforded; its spectral data were quite different from those expected for the corresponding diazepine. The product contained a cyano group and an imino group, which were confirmed by ${ }^{13} \mathrm{C}$ NMR and IR spectra. Its ${ }^{1} \mathrm{H}$ NMR spectrum was similar to that of the hydrazone $\mathbf{5 h}$ except for the disappearance of the singlet signal of the acidic $\alpha$-proton $\left(\mathrm{H}_{\mathrm{h}}\right)$. In addition, a DEPT experiment showed that the methyne carbon $\left(\mathrm{C}_{\mathrm{h}}\right)$ had changed to a quaternary carbon, which suggested that the nitrogen atom of the hydrazone attacked the methyne carbon to form a six-membered ring. The empirical formula $\mathrm{C}_{14} \mathrm{H}_{15} \mathrm{~N}_{5} \mathrm{O}_{3}$ also indicated that dehydration proceeded during the ring construction. On the basis of these spectral and analytical data, the product was determined to be the pyridazine

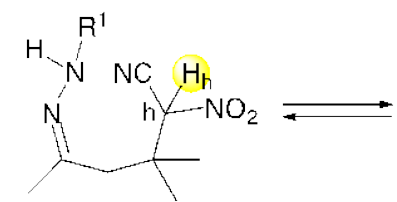

$5 h, i$

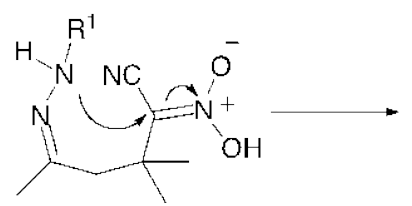

$11 \mathrm{~h}, \mathrm{i}$<smiles>[R1]N1N=C(C)CC(C)(C)C1(C#N)N(O)O</smiles>

$12 \mathrm{~h}, \mathrm{i}$

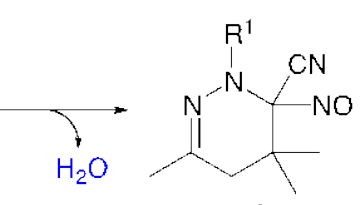

$13 \mathrm{~h}, \mathrm{i}$
Scheme 4. A plausible mechanism for the formation of the pyridazines 13h,i.

13h (Scheme 4). ${ }^{15}$ 2,4-Dinitrophenylhydrazone $5 \mathbf{i}$ was also transformed to the pyridazine $\mathbf{1 3 i}$ in a similar way (at $70{ }^{\circ} \mathrm{C}$, in $69 \%$ yield).

Thus, the reactivity of $\mathbf{1}$ with $\mathbf{2}$ varied with the hydrazine substituent used (Scheme 5). These differences are attributed to the inherent basicities and nucleophilicities of the hydrazines 2 and the hydrazones $\mathbf{5}$. The more basic hydrazines $\mathbf{2 a - d}$ (unsubstituted and alkyl substituted) easily formed the hydrazinium salts 3a-d, which were observed by ${ }^{1} \mathrm{H}$ NMR. When the hydrazine was liberated under equilibrium, the pseudointramolecular hydrazonation proceeded and afforded 5a-d. However, the nitrogens of $\mathbf{5 a}-\mathbf{c}$ were so nucleophilic that ring closure occurred very quickly to afford the diazepines $\mathbf{6 a}-\mathbf{c}$, among which $\mathbf{6 a}$ could be converted to stable $\mathbf{7 a}$

In the case of the aromatic hydrazines $\mathbf{2 e - i}$, although the hydrazinium salts $\mathbf{3 e - i}$ were the most likely to be formed, they were hardly detected by ${ }^{1} \mathrm{H}$ NMR because the equilibrium shifted to the intimate-pair $\mathbf{4}$ owing to the low basicity of $\mathbf{2 e}-\mathbf{i}$. Thus, the

$$
1
$$$$
\mathrm{R}^{1} \mathrm{NHNH}_{2}
$$<smiles>C/C(CC(C)(C)C(C#N)[N+](=O)[O-])=N/N</smiles>
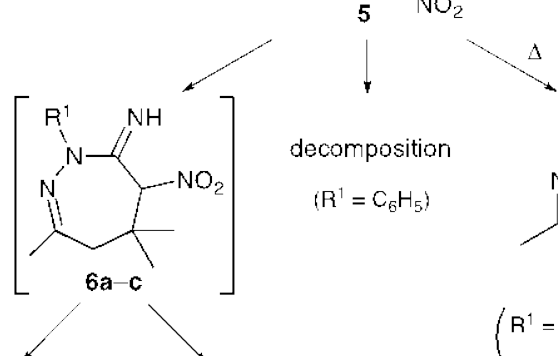

decomposition

$\left(\mathrm{R}^{1}=\mathrm{C}_{6} \mathrm{H}_{5}\right)$

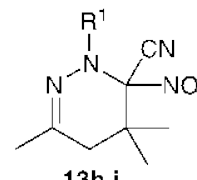

$13 \mathrm{~h}, \mathrm{i}$

$\left(\begin{array}{c}\mathrm{R}^{1}= \\ \begin{array}{c}4-\mathrm{NO}_{2} \mathrm{C}_{6} \mathrm{H}_{4} \\ 2,4-\left(\mathrm{NO}_{2}\right)_{2} \mathrm{C}_{6} \mathrm{H}_{3}\end{array}\end{array}\right)$

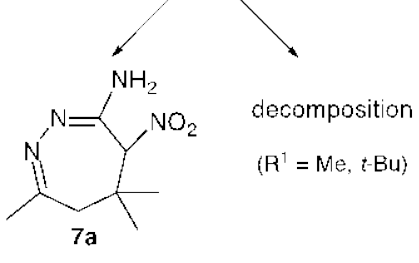

$\left(\mathrm{R}^{1}=\mathrm{H}\right)$

Scheme 5

hydrazones $\mathbf{5 e - i}$ were immediately afforded by a pseudointramolecular process just after the salts $\mathbf{3 e - i}$ were formed. An aromatic ring with an electron-withdrawing substituent can stabilize the hydrazone and decrease the nucleophilicity of the neighboring nitrogen, which facilitates the isolation of the

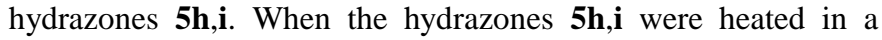
polar solvent, tautomerization of the nitro group occurred, affording the nitronic acids $\mathbf{1 1 h}, \mathbf{i}$, and the $\mathrm{C}_{\mathrm{h}}$-carbon became sufficiently electrophilic to be attacked by the anilino nitrogen to form the pyridazine frameworks of $\mathbf{1 2 h}, \mathbf{i}$. The results of DFT calculations (B3LYP/6-31++G*) of model compounds 14 and 15 showed the considerably higher electrophilicity of the nitronic acid carbon $\left(\mathrm{C}_{\mathrm{i}}\right)$ compared to a cyano group, which is in good agreement with the experimental results (Figure 4).

In summary, we successfully synthesized diazepine $\mathbf{7 a}$ and pyridazines $\mathbf{1 3 h}$,i by treating keto nitrile $\mathbf{1}$ with hydrazines under mild conditions, which involved pseudo-intramolecular hydrazonation as a key step. In addition, the intermediate hydrazones $\mathbf{5 h}$,i were successfully isolated when 4-nitrophenyland 2,4-dinitrophenylhydrazines $\mathbf{2 h}$,i were used. Moreover, the DFT calculations supported the experimental results reasonably. Consequently, the present pseudo-intramolecular process will be applicable as an efficient protocol in synthetic chemistry, provided suitably designed substrates satisfying the two criteria are employed. 


\section{Acknowledgments}

This work was supported by Grants-in-Aid for Scientific Research (No. 22550043) from Japan Society for the Promotion

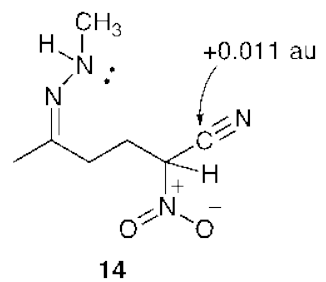

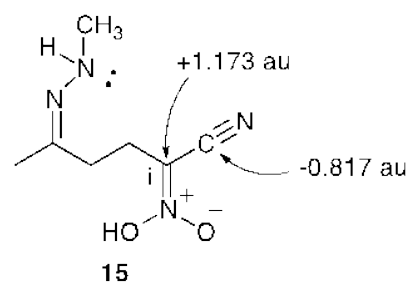

Figure 4. Mulliken populations determined by DFT calculations (B3LYP/6-31++G*).

of Science.

\section{References and notes}

1. (a) Trost, B. M.; Shi, Y. J. Am. Chem. Soc. 1992, 114, 791. (b) Trost, B. Acc. Chem. Res. 2002, 35, 695. (c) Young, I. S.; Baran, P. S. Nature Chem. 2009, 1, 193.

2. (a) Koblenz, T. S.; Wassenaar, J.; Reek, J. N. H. Chem. Soc. Rev., 2008, 37, 247. (b) Vriezema, D. M.; Aragonès, M. C.; Elemans, J. A. A. W.; Cornelissen, J. J. L. M.; Rowan, A. E.; Nolte, R. J. M. Chem. Rev. 2005, 105, 1445.

3. Yoshizawa, M.; Fujita, M. Pure Appl. Chem., 2005, 77, 1107.

4. Yoshizawa, M.; Klosterman, J. K.; Fujita, M. Angew. Chem., Int. Ed. 2009, 48, 3418.

5. (a) Onel, L.; Buurma, N. J. Annu. Rep. Prog. Chem., Sect. B, 2009, 105, 363. (b) Dwars, T.; Paetzold, E.; Oehme, G. Angew. Chem., Int. Ed., 2005, 44, 7174.

6. (a) Nishiwaki, N.; Nishida, D.; Ohnishi, T.; Hidaka, F.; Shimizu, S.; Tamura, M.; Hori, K.; Tohda, Y.; Ariga, M. J. Org. Chem., 2003, 68, 8650. (b) Nakaike, Y.; Taba, N.; Itoh, S.; Tobe, Y.; Nishiwaki, N.; Ariga, M. Bull. Chem. Soc. Jpn., 2007, 80, 2413.
7. We consider Ballini's reactions proceed also in a pseudointramolecular process; Ballini, R.; Bosica, G.; Fiorini, D. Tetrahedron, 2003, 59, 1143.

8. The keto nitrile $\mathbf{1}$ was readily prepared from commercially available ethyl nitroacetate via three steps; Nishiwaki, N.; Nogami, T.; Ariga, M. Heterocycles, 2008, 75, 675.

9. Nishiwaki, N.; Kakutani, K.; Tamura, M.; Ariga, M. Chem. Lett., 2009, 38, 680 .

10. Nishiwaki, N.; Hirao, S.; Sawayama, J.; Saigo, K.; Kobiro, K. Chem. Commun. 2011, 47, 4938.

11. The diazepine 7a. Yellow solid. Mp 113-115 C. IR (Nujol) 1634, 1549, 1462, $1348 \mathrm{~cm}^{-1} ;{ }^{1} \mathrm{H}$ NMR $\left(\mathrm{CDCl}_{3}\right) \delta 0.91(\mathrm{~s}, 3 \mathrm{H}), 1.07$ (s, 3H), 2.17 (s, 3H), 2.17 (d, $J=19.0 \mathrm{~Hz}, 1 \mathrm{H}), 2.52$ (d, $J=19.0 \mathrm{~Hz}$, 1H), 4.83 (s, $1 \mathrm{H}), 6.35$ (br s, $2 \mathrm{H}) ;{ }^{13} \mathrm{C} \mathrm{NMR}\left(\mathrm{CDCl}_{3}\right) \delta 25.8\left(\mathrm{CH}_{3}\right)$, $26.6\left(\mathrm{CH}_{3}\right), 27.7\left(\mathrm{CH}_{3}\right), 33.1(\mathrm{C}), 41.7\left(\mathrm{CH}_{2}\right), 90.7(\mathrm{CH}), 137.7(\mathrm{C})$, $172.2(\mathrm{C})$. Analytical data were not given satisfactorily because of instability of $\mathbf{7 a}$.

12. For details about the reaction toward the diazepine 7a monitored by ${ }^{1} \mathrm{H}$ NMR, see Supporting Information.

13. For details about the formation of the hydrazinium salt $\mathbf{3 b}$ monitored by ${ }^{1} \mathrm{H}$ NMR, see Supporting Information.

14. The hydrazone $5 \mathbf{h}$. Pale yellow needles. Mp 138-139 ${ }^{\circ} \mathrm{C}$. IR (KBr) 1603, 1560, 1321, $1306 \mathrm{~cm}^{-1} ;{ }^{1} \mathrm{H}$ NMR $\left(\mathrm{CDCl}_{3}\right) \delta 1.33(\mathrm{~s}, 3 \mathrm{H})$, 1.41 (s, 3H), 2.01 (s, 3H), 2.53 (d, $J=16.4 \mathrm{~Hz}, 1 \mathrm{H}), 2.66$ (d, $J=$ $16.4 \mathrm{~Hz}, 1 \mathrm{H}), 6.04$ (s, 1H), 7.01 (d, $J=9.2 \mathrm{~Hz}, 2 \mathrm{H}), 7.56$ (br s, $1 \mathrm{H}), 8.18(\mathrm{~d}, J=9.2 \mathrm{~Hz}, 2 \mathrm{H}) ;{ }^{13} \mathrm{C}$ NMR $\left(\mathrm{CDCl}_{3}\right) \delta 17.2\left(\mathrm{CH}_{3}\right)$, $24.3\left(\mathrm{CH}_{3}\right), 24.8\left(\mathrm{CH}_{3}\right), 39.9(\mathrm{C}), 47.0\left(\mathrm{CH}_{2}\right), 83.7(\mathrm{CH}), 111.5$ (C), $111.9(\mathrm{CH}), 126.2(\mathrm{CH}), 140.8(\mathrm{C}), 145.4(\mathrm{C}), 149.6$ (C); MS (FAB) $320\left(\mathrm{M}^{+}+1,100\right)$. Anal. Calcd for $\mathrm{C}_{14} \mathrm{H}_{17} \mathrm{~N}_{5} \mathrm{O}_{4}$ : C, 52.66; $\mathrm{H}$, 5.37; N, 21.93. Found: C, 52.66; H, 5.52; N, 21.95.

15. The pyridazine $13 \mathrm{~h}$. Orange plates. Mp $146-148^{\circ} \mathrm{C}$. IR (Nujol) 2210, 1612, 1537, $1348 \mathrm{~cm}^{-1}$; ${ }^{1} \mathrm{H}$ NMR $\left(\mathrm{CDCl}_{3}\right) \delta 1.29(\mathrm{~s}, 3 \mathrm{H})$, 1.46 (s, 3H), 1.81 (s, 3H), 2.34 (d, $J=14.0 \mathrm{~Hz}, 1 \mathrm{H}), 2.57$ (d, $J=$ $14.0 \mathrm{~Hz}, 1 \mathrm{H}), 7.91$ (d, $J=9.0 \mathrm{~Hz}, 2 \mathrm{H}), 8.37(\mathrm{~d}, J=9.0 \mathrm{~Hz}, 2 \mathrm{H})$; ${ }^{13} \mathrm{C}$ NMR (DMSO-d $\left.d_{6}\right) \delta 20.3\left(\mathrm{CH}_{3}\right), 26.5\left(\mathrm{CH}_{3}\right), 27.1\left(\mathrm{CH}_{3}\right), 39.5$ (C), $45.0\left(\mathrm{CH}_{2}\right), 103.4(\mathrm{C}), 111.3(\mathrm{C}), 123.5(\mathrm{CH}), 125.0(\mathrm{CH})$, 126.3 (C), 149.1 (C), 153.5 (C); MS (FAB) $302\left(\mathrm{M}^{+}+1,100\right)$. Anal. Calcd for $\mathrm{C}_{14} \mathrm{H}_{15} \mathrm{~N}_{5} \mathrm{O}_{3}$ : C, 55.81; H, 5.02; N, 23.24. Found: C, 55.74; H, 4.77; N, 23.07. 